\title{
USO DE CAMA DE AVES NA ADUBAÇÃO DA CULTURA DO MILHO
}

\author{
Edson Corrêa Goulart ${ }^{1}$; Murilo Campos Ribeiro ${ }^{1}$, Luciana Maria de Lima ${ }^{2}$; Brunna \\ Michelly Aparecida Rodrigues ${ }^{3}$ \\ 1 Engenheiro Agrônomo \\ 2 Professora Doutora do Curso de Engenharia Agronômica da Fundação \\ Carmelitana Mário Palmério- FUCAMP. Monte Carmelo, Brasil. e-mail: \\ Idu.lima@gmail.com \\ 3 Graduanda Engenharia Agronômica- FUCAMP
}

Recebido em: 08/09/2015 - Aprovado em: 14/11/2015 - Publicado em: 01/12/2015 DOI: http://dx.doi.org/10.18677/Enciclopedia_Biosfera_2015_239

\begin{abstract}
RESUMO
O uso de resíduos orgânicos pode-se tornar prática útil para os produtores, contribuindo para melhorar a fertilidade e conservação do solo e maior aproveitamento dos recursos existentes na propriedade. O presente trabalho teve como objetivo avaliar a produtividade de milho e as propriedades químicas do solo adubado com cama de peru "in natura" e compostada, aplicada a lanço ou incorporada ao solo. Os tratamentos utilizados foram: cama de peru "in natura" incorporada ao solo cama de peru "in natura" não incorporada, composto orgânico incorporado ao solo, cama de peru compostada não incorporado e uma testemunha com fertilizante mineral. O delineamento experimental foi em blocos casualizados com cinco tratamentos e quatro repetições. Após a aplicação dos tratamentos, sementes do híbrido RB 9308 Yieldgard foram semeadas nas parcelas. Após atingir maturidade as espigas foram colhidas e debulhadas para cálculo da produtividade. Amostras de solo foram coletadas logo após a colheita do milho para determinação das propriedades químicas do solo. Para produtividade do milho não houve diferença significativa entre os tratamentos, exceto entre os tratamentos para os teores de Boro (B) e Manganês (Mn). A cama de peru aplicada incorporada e não incorporada incrementou os teores de B no solo. De forma semelhante, o composto orgânico não incorporado incrementou os teores de Mn no solo. Todos os demais atributos químicos analisados não foram influenciados significativamente pela adição dos adubos orgânicos quando comparados com a testemunha, independente da forma de aplicação no solo (incorporado ou não incorporado).
\end{abstract}

PALAVRAS-CHAVE: composto orgânico, produtividade. Zea mays,

\section{USE POULTRY LITTER IN FERTILIZER OF CROP MAIZE}

\begin{abstract}
Use of organic composed may become useful practice for providers, contributing for improving fertility and conservation of ground and larger profit of resources existing in property. The present work had as objective to evaluate corn productivity and the chemical proprieties of the ground fertilized with turkey bed, in natura and composed, applied to haul and incorporated to the ground. The treatment used were: in natura incorporated turkey bed, organic composed incorporated to the ground, turkey bed
\end{abstract}


composed not incorporated and a witness with mineral fertilizer. The experimental outline was in casually blocks, with five treatments and four repetitions. After treatments apply, seeds of hybrid RB 9308 were seeded in parts. After reaching maturity, crops were collected and threshed for productivity calculation. Ground samples were collected soon after corn harvest for ground chemical proprieties determination. For corn productivity, there were no meaningful difference among treatments, except between treatments for Boron (B) and Manganese (Mm) contents. Turkey bed applied incorporated and not incorporated has increased B contents in ground. Similarly, not incorporated organic composed has increased Mn contents in ground. All the others chemical attributes analyzed were not meaningfully influenced by addition of organic fertilizers when compared with witness, independent of apply way in ground (incorporated and not incorporated).

KEYWORDS: Zea mays, organic composed, productivity.

\section{INTRODUÇÃO}

A avicultura brasileira apresentou, nas últimas décadas, alto índice de crescimento destacando-se como terceiro maior produtor mundial e líder em exportação (MAPA, 2015). No Brasil existe um rebanho de 5,5 bilhões de cabeças de frango de corte e postura capazes de gerar resíduos orgânicos (IBGE-SIDRA, 2010) que podem ser utilizadas na agricultura.

Com a crescente produção avícola faz-se necessário buscar alternativas para - aproveitamento seguro e o manejo adequado dos resíduos para evitar contaminação do ambiente. Aliado ao elevado preço dos fertilizantes, a adubação de culturas com resíduos orgânicos torna-se uma alternativa interessante, principalmente, quando é gerado dentro da propriedade rural.

Além de reduzir custos, os dejetos de aves são uma excelente fonte de nutrientes e quando manejados adequadamente, podem suprir, parcial ou totalmente, o fertilizante químico. Ademais, o seu uso adiciona matéria orgânica que melhora os atributos físicos do solo, aumenta a capacidade de retenção de água, reduz a erosão, melhora a aeração e cria um ambiente mais adequado para o desenvolvimento da flora microbiana do solo. Porém, devem ser utilizados com critérios para evitar desequilíbrios e contaminação do ambiente (MENEZES et al. 2004).

Assim, tendo em vista o potencial aproveitamento da cama de aves e a falta de informações a respeito das formas de aplicação, esse ensaio teve como objetivos: avaliar a produtividade do milho adubado com cama de peru, antes e após compostagem, aplicados à lanço e incorporados ao solo e quantificar o residual de nutrientes no solo, após colheita do milho.

\section{MATERIAL E MÉTODOS}

O experimento foi instalado na área experimental da Fundação Carmelitana Mário Palmério - FUCAMP, localizada em Monte Carmelo, Minas Gerais. A área está localizada à $885 \mathrm{~m}$ de altitude e as coordenadas geográficas são: 1845'037" latitude e longitude 4729'774". Antes da instalação do experimento, foi efetuada a aração, gradagem e nivelamento do solo. Amostras de solo foram coletadas para análise e os resultados obtidos constam nas Tabelas 1 e 2. 
TABELA 1 - Análise química do solo na camada de 0-20 cm. Monte Carmelo- MG, 2013

\begin{tabular}{ccccccccc}
\hline $\mathbf{p H}$ & $\mathbf{P}$ & $\mathbf{K}^{+}$ & $\mathbf{C a}^{2+}$ & $\mathbf{M g}^{2+}$ & $\mathbf{A l}^{2+}$ & $\mathbf{H}+\mathbf{A l}$ & $\mathbf{V}$ & $\mathbf{M o}$ \\
\hline & $\ldots \mathrm{mg} \mathrm{dm}{ }^{-3} \ldots$ & & $\ldots \ldots \ldots \ldots \ldots \ldots \mathrm{mg} \mathrm{dm}^{-3} \ldots \ldots \ldots \ldots \ldots \ldots$ & $\ldots \ldots \ldots$ & $\ldots$ dagkg $^{-1} \ldots$ \\
6,3 & 5,5 & 0,41 & 2,9 & 2,4 & 0,04 & 1,7 & 76 & 3,6 \\
\hline
\end{tabular}

TABELA 2 - Análise textural do solo. Monte Carmelo- MG, 2013

\begin{tabular}{ccc}
\hline Areia & Silte & Argila \\
\hline & $\ldots \ldots \ldots \ldots \ldots \mathrm{ggg}^{-1} \ldots \ldots \ldots \ldots \ldots \ldots \ldots \ldots \ldots \ldots$ & \\
525 & 100 & 375 \\
\hline
\end{tabular}

Os tratamentos comparados no presente ensaio foram: cama de peru "in natura" incorporada ao solo (cama de peru I), cama de peru "in natura" não incorporada (cama de peru NI), composto orgânico incorporado ao solo (composto I), cama de peru compostada não incorporado (composto $\mathrm{NI}$ ) e uma testemunha com fertilizante mineral. A cama de peru e o composto foram aplicados no solo na quantidade de $4 \mathrm{t} \mathrm{ha}^{-1}$. Na testemunha utilizou-se $600 \mathrm{~kg} \mathrm{ha}^{-1}$ do formulado 04-30-10. O resultado da composição química da cama de peru e do composto encontra-se na tabela 3.

TABELA 3- Composição química dos adubos orgânicos aplicados no solo. Monte Carmelo- MG, 2014

\begin{tabular}{|c|c|c|c|c|c|c|}
\hline Tratamentos & MO & $\mathrm{P}_{2} \mathrm{O}_{5}$ & $\mathrm{~K}_{2} \mathrm{O}$ & $S$ & $\mathrm{Ca}$ & $\mathrm{Mg}$ \\
\hline Cama de peru & 31,3 & 1,6 & $\begin{array}{c}\ldots \ldots \% \\
1,4\end{array}$ & 0,12 & 0,66 & 0,27 \\
\hline \multirow[t]{2}{*}{ Composto } & 34,4 & 0,7 & 1,5 & 0,27 & 1,06 & 0,27 \\
\hline & $\begin{array}{c}\text { CTC } \\
\mathrm{cmol}_{\mathrm{C}} \mathrm{kg}^{-1}\end{array}$ & B & $\mathrm{Cu}$ & $\begin{array}{c}\mathrm{Fe} \\
\mathrm{mg} \mathrm{kg}^{-1}\end{array}$ & $\mathrm{Mn}$ & $\mathrm{Zn}$ \\
\hline Cama de peru & 24 & 8 & 64 & 6574 & 255 & 76 \\
\hline Composto & 30 & 13 & 209 & 8306 & 235 & 243 \\
\hline
\end{tabular}

* Extrator: P, K, Ca, Mg, S, Na, Cu, Fe, Mn, Zn = Digestão Nitro Perclórico; B: incineração.

A semeadura do milho foi realizada dia 27 de outubro de 2013 e o híbrido utilizado foi Yieldgard RB 9308. As parcelas foram constituídas de $10 \mathrm{~m} \times 6 \mathrm{~m}$, sendo considerado como área útil, quatro linhas de $4 \mathrm{~m}$ no centro das parcelas, e o restante para formação da bordadura. Aos 18 dias após o plantio aplicou-se $2 \mathrm{~kg}$ de uréia por parcela na adubação de cobertura. $\mathrm{O}$ controle de plantas infestantes foi realizado por meio de capina manual, e não houve necessidade de controle de pragas e doenças. Após atingir a maturação fisiológica, as espigas de parcelas foram colhidas manualmente e debulhadas para determinar a produtividade.

Após a colheita do milho, foi retirada uma amostra composta de cada parcela para determinar os teores de macro e micronutrientes, $\mathrm{pH}$ e matéria orgânica no solo. Para isso, foram retiradas cinco amostras simples por parcela com auxílio de 
trado holandês, na profundidade de $0-20 \mathrm{~cm}$. As amostras foram homogeinizadas em balde limpo para formação da amostra composta que foi enviada ao laboratório para análise, conforme metodologia EMBRAPA (1999).

O delineamento experimental empregado foi em blocos casualizados com cinco tratamentos e quatro repetições. A análise estatística do experimento foi realizada no programa SISVAR, versão 4.6 (Build 6.1) do qual foi obtida a análise de variância. As variáveis significativas no teste $F$ foram submetidas ao teste de média.

\section{RESULTADOS E DISCUSSÃO}

A produtividade do milho adubado com composto e cama de peru não diferiu da adubação com fertilizante químico, independente se incorporada ou não incorporada ao solo (Tabela 4). Apesar de ter sido conduzido por apenas uma safra, os resultados desse ensaio foram promissores e além do mais, é crescente a demanda por esse tipo de resíduo para adubação de culturas.

TABELA 4- Produtividade de milho adubado com fertilizante químico e orgânico. Monte Carmelo, 2014

\begin{tabular}{lc}
\hline Tratamentos & Produtividade $\left(\mathrm{kg} \mathrm{ha}^{-1}\right)$ \\
\hline Fertilizante & $10406 \mathrm{a}$ \\
Cama peru I & $13227 \mathrm{a}$ \\
Cama peru NI & $12666 \mathrm{a}$ \\
Composto I & $13500 \mathrm{a}$ \\
Composto NI & $13241 \mathrm{a}$ \\
\hline
\end{tabular}

Médias seguidas de mesma letra, minúscula na coluna, não diferem pelo teste de Tukey a $5 \%$ probabilidade.

O uso das camas de aves como fertilizante agrícola, é uma opção interessante, uma vez que, o material apresenta nutrientes que podem ser incorporados ao solo garantindo a produtividade das lavouras e pode auxiliar na redução de custos com fertilizantes (MENEZES et al. 2004).

Em estudos para avaliar o efeito de doses de cama de aves e tempos de incubação, no desenvolvimento inicial de plantas de milho, SILVA et al. (2011) verificaram que o suprimento de 10,5 gramas de cama de frango por quilo de solo, o equivalente a 15,8 $\mathrm{t} \mathrm{ha}^{-1}$, incubadas por trinta dias, promoveram maior altura de plantas e massa seca de folhas e colmos de milho.

A utilização de matéria orgânica no solo na forma de adubos orgânicos, de acordo com a decomposição dos resíduos, pode ter efeito imediato no solo, ou efeito residual, através de um processo mais lento de decomposição. Trabalhos realizados com hortaliça foram observados aumentos na produção e nos teores de nutrientes nas plantas, após a aplicação de adubos orgânicos (RODRIGUES, 1990).

Houve efeito significativo da adubação orgânica nos teores de Boro (B) e Manganês (Mn) (Tabela 5). A cama de peru "in natura" aplicada incorporada e não incorporada incrementou os teores de B no solo e foram estatisticamente diferentes da testemunha com adubação mineral.

De forma semelhante, cama de peru compostada não incorporado incrementou os teores de $\mathrm{Mn}$ no solo e apresentou diferença estatística em relação a testemunha. Todos os demais atributos químicos analisados não foram influenciados significativamente pela adição dos adubos orgânicos quando ENCICLOPÉDIA BIOSFERA, Centro Científico Conhecer - Goiânia, v.11 n.22; p.2745 
comparados com a testemunha, independente da forma de aplicação no solo (incorporado ou não incorporado).

Estes resultados estão de acordo com SCHERER et al. (2007), que não constataram efeitos da aplicação de esterco de suínos nas doses de 40 e $115 \mathrm{~m}^{3}$ ha ${ }^{1}$ durante quatro anos, sobre os fatores de acidez do solo, cátions básicos ( $\mathrm{Ca}, \mathrm{Mg} \mathrm{e}$ K), CTC e teor de matéria orgânica do solo.

O fato de a aplicação de cama de peru não resultar em incrementos nos teores de macro e micronutrientes ( $\mathrm{P}, \mathrm{K}, \mathrm{S}, \mathrm{Ca}, \mathrm{Mg}, \mathrm{Cu}, \mathrm{Fe}$ e $\mathrm{Zn}$ ) no solo, exceto para o $\mathrm{B}$ e $\mathrm{Mn}$ pode estar relacionado com teores desses elementos nos adubos orgânicos, associado aos teores já elevados no solo. Além disso, deve ser considerado a extração de nutrientes pela cultura do milho. Os atributos não afetados significativamente pelos tratamentos são apresentados em valores médios na Tabela 5.

TABELA 5- Valores médios de macro e micronutrientes, $\mathrm{pH}$, acidez potencial $(\mathrm{H}+\mathrm{Al})$, capacidade de troca catiônica $(\mathrm{T})$, matéria orgânica $(\mathrm{MO})$ e saturação de bases (V) considerando a aplicação de adubos orgânicos em um solo após o cultivo de milho.

\begin{tabular}{|c|c|c|c|c|c|c|c|c|}
\hline \multirow[t]{2}{*}{ Tratamentos } & $\mathrm{P}$ & $\mathrm{K}$ & $\mathrm{S}$ & $\mathrm{Ca}$ & & $\mathrm{H}+\mathrm{Al}$ & $\mathrm{Al}$ & $\mathrm{T}$ \\
\hline & \multicolumn{8}{|c|}{$\ldots \ldots \ldots \ldots \mathrm{mg} \mathrm{dm}^{-3} \ldots \ldots \ldots$} \\
\hline Composto $\mathrm{I}^{(1)}$ & 5,6 & 101 & 7,5 & 4,5 & 2,6 & 2,1 & 0,0 & 9,5 \\
\hline Composto $\mathrm{NI}^{(2)}$ & 4,3 & 101 & 7,0 & 4,6 & 2,4 & 2,0 & 0,0 & 9,2 \\
\hline Formulado & 6,0 & 71 & 8,0 & 4,6 & 2,3 & 2,1 & 0,0 & 9,1 \\
\hline Cama de peru I & 6,6 & 106 & 7,8 & 4,5 & 2,4 & 2,0 & 0,0 & 9,2 \\
\hline \multirow[t]{3}{*}{ Cama de peru NI } & 5,1 & 104 & 7,0 & 3,2 & 1,8 & 2,2 & 0,0 & 7,5 \\
\hline & $\begin{array}{c}\mathrm{pH} \\
\text { (água) }\end{array}$ & $B$ & $\mathrm{Cu}$ & $\mathrm{Fe}$ & $\mathrm{Mn}$ & $\mathrm{Zn}$ & $\mathrm{MO}$ & V \\
\hline & \multicolumn{8}{|c|}{ 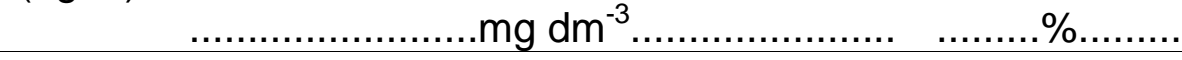 } \\
\hline Composto $I^{(1)}$ & 6,9 & $0,16 b c$ & 4,7 & 30,0 & 7,9 ab & 1,6 & 3,7 & 78 \\
\hline Composto $\mathrm{NI}^{(2)}$ & 7,0 & $0,14 \mathrm{c}$ & 4,9 & 32,7 & $9,4 \mathrm{a}$ & 1,9 & 3,6 & 78 \\
\hline Formulado & 6,8 & $0,14 \mathrm{c}$ & 4,9 & 31,5 & $7,6 \mathrm{~b}$ & 1,9 & 3,6 & 77 \\
\hline Cama de peru I & 6,9 & $0,19 a b$ & 5,1 & 32,5 & $9,1 \mathrm{ab}$ & 1,9 & 3,4 & 78 \\
\hline Cama de peru NI & 6,8 & $0,21 \mathrm{a}$ & 5,5 & 37,7 & $8,3 \mathrm{ab}$ & 2,5 & 3,5 & 64 \\
\hline
\end{tabular}

* Extratores: P, K: Mehlich-1; S: fosfato monobásico de cálcio; Ca, Mg, Al: cloreto de potássio; $\mathrm{H}+\mathrm{Al}$ : solução tampão SMP pH 7,5; B: água quente + cloreto de bário; $\mathrm{Cu}, \mathrm{Fe}, \mathrm{Mn}, \mathrm{Zn}$ : DTPA; $\mathrm{MO}$ : dicromato de sódio $+\mathrm{HCl}$.

** (1) Incorporado; (2) Não incorporado.

*** (3) Médias seguidas pela mesma letra não diferem entre si pelo teste de Tukey a $5 \%$ de probabilidade.

Conforme dados da literatura, diversos são os benefícios do emprego de adubos orgânicos na melhoria da qualidade do solo e, consequentemente, no desenvolvimento e produtividade das culturas.

Em relação à matéria orgânica (MO), a aplicação dos adubos orgânicos também não resultou em incrementos em relação à testemunha, fato que pode estar relacionado ao aumento na atividade microbiana durante o verão, devido à alta temperatura e umidade do solo. Além disso, o fator que mais influencia a ENCICLOPÉDIA BIOSFERA, Centro Científico Conhecer - Goiânia, v.11 n.22; p.2746 2015 
persistência da matéria orgânica no solo é a sua própria proteção física, originada pela interação com a argila. O solo do presente trabalho, com teor de argila de $37,5 \%$ pode favorecer a decomposição da $\mathrm{MO}$, proporcionando um estado estacionário da matéria orgânica, com quantidades adicionadas e perdidas equivalentes.

A matéria orgânica de origem animal ou vegetal exerce, quando fornecida em dose adequada, efeitos positivos sobre o rendimento das culturas devido principalmente ao complexo de nutrientes nela contidos e aumento da disponibilidade de nutrientes na fase solúvel do solo para as plantas (RODRIGUES et al., 2009).

De acordo com pesquisas, a aplicação de compostos ou resíduos orgânicos no solo aumentam os teores de nutrientes no solo, entretanto, este efeito tem sido observado em trabalhos a longo prazo, com aplicações contínuas e em maior volume. CERETTA et al. (2003) observaram que a aplicação de esterco líquido de suínos nas doses de 20 e $40 \mathrm{~m}^{3}$ ha $^{-1}$, aplicado em intervalos de 45 a 60 dias incrementou grandes quantidades de nutrientes ao solo, elevando principalmente os teores de $\mathrm{P}, \mathrm{Ca}$ e $\mathrm{Mg}$ em áreas sob pastagem natural. De forma semelhante, em um estudo realizado com aplicação de esterco bovino utilizando-se doses de 12 a $20 \mathrm{t}$ ha $^{-1}$ em 22 áreas, no Estado de Pernambuco, concluiu-se que o esterco resultou em acumulações nos teores de $\mathrm{MO}, \mathrm{N}, \mathrm{Ca}, \mathrm{P}$ total, $\mathrm{K}$ e $\mathrm{Mg}$ até a profundidade de 0-60 cm (GALVÃO et al., 2008).

Apesar de ter ocorrido incrementos apenas de B e Mn no solo neste trabalho, a aplicação de adubos orgânicos possui grande relevância para produção sustentável das culturas agrícolas, e é importante salientar que se faz necessário conduzir trabalhos com aplicação de maiores doses de adubação orgânica durante duas ou mais safras de milho.

\section{CONCLUSÃO}

A produtividade do milho adubado com cama de frango não compostada e compostada não diferiram do fertilizante químico.

A aplicação de composto orgânico e cama de peru afetaram os teores de B e Mn no solo. Os demais atributos químicos analisados não apresentaram diferença significativa, independentemente do tipo de adubo (composto ou cama de peru) e da forma de aplicação (incorporado ou não incorporado).

\section{REFERÊNCIAS}

CERETTA, C.A; DURIGON, R.; BASSO, C.J.; BARCELLOS, L.A.R.; VIEIRA, F.C.B. Características químicas de solo sob aplicação de esterco líquido de suínos em pastagem natural. Pesquisa Agropecuária Brasileira, v.38, p.729-735, 2003.

EMPRESA BRASILEIRA DE PESQUISA AGROPECUÁRIA. Manual de análises química de solos e fertilizantes. Brasília, DF,1999. 370p.

GALVÃO, S.R.S.; SALCEDO, I.H.; OLIVEIRA, F.F. Acumulação de nutrientes em solos arenosos adubados com esterco bovino. Pesquisa Agropecuária Brasileira, v.43, p.99-105, 2008.

IBGE - Instituto Brasileiro de Geografia e Estatística. Disponível em: http://www.ibge.gov.br, acesso em janeiro de 2010. 
MAPA-Ministério da agricultura, pecuária e abastecimento; Disponível em: http://www.agricultura.gov.br/animal/especies/aves, acesso em setembro de 2015.

MENEZES, J. F. S.; ALVARENGA, R. C.; SILVA, G. P.; KONZEN, E. A.; PIMENTA, F. F. Cama-de-frango na agricultura: perspectivas e viabilidade técnica e econômica. Boletim técnico, a1. n.3. 28 p, 2004.

SCHERER, E.E.; BALDISSERA, I.T.; NESI, C.N. Propriedades químicas de um latossolo vermelho sob plantio direto e adubação com esterco de suínos. Revista Brasileira de Ciência do Solo, v.31, p.123-131, 2007.

SILVA, T. R.; MENEZES J. F. S.; SIMON, G. A.; ASSIS, L.A.; SANTOS, C. J. L.; GOMES, V.G. Cultivo do milho e disponibilidade de $P$ sob adubação com cama-defrango. Revista Brasileira de Engenharia Agrícola e Ambiental. v.15, n.9, p.903910, 2011.

RODRIGUES, E. T. Efeitos das adubações orgânica e mineral sobre o acúmulo de nutrientes e sobre o crescimento da alface (Lactuca sativa L.). Viçosa, MG: UFV, 1990.60 p. Dissertação de Mestrado. 